\title{
AOIR
}

Selected Papers of \#AoIR2020:

The 21 ${ }^{\text {st }}$ Annual Conference of the Association of Internet Researchers Virtual Event / 27-31 October 2020

\section{ACTIVIST BROWSER EXTENSIONS AS INTERFACE DÉTOURNEMENT: REMINDING, COPING, AND INFRASTRUCTURAL ALIGNMENT}

Tiancheng Cao

The University of Texas at Austin

\section{Introduction}

This paper investigates web browser extensions as an under-researched media object for their capacity for activism. The relevance of the study stems from the ubiquity of the web browser as a communication tool and its increasing power in shaping how web content is delivered to users. Browser extensions typically customize the functionality of a webpage, but some creators have used them to foreground highly contested social issues. One early example is Facebook Demetricator, which removes all the metrics from Facebook's user interface and highlights the dependence of social media platforms on the quantification of user activities. This particular extension has been studied in the existing literature as a practice of design activism (Lievrouw, 2018), countergamification (Dragona, 2014), and resistance against digital surveillance (Zuboff, 2019), but the browser extension in general, including its behavioral pattern, capacity for activism, and relationship with the browser platform, has yet to be thoroughly examined.

"Activist extensions" disrupt a webpage's intended use and redirect users' attention by modifying textual, visual, or auditory elements of the web user interface. This paper generates a typology of existing activist extensions and provides a theoretical framework to analyze their operations as a process of interface modification, a relationship to users, and a counteract to the browser platform's means of governance. Based on these considerations, this study asks: How do activist extensions redirect users' attention from the webpage to real-world social issues? What are the potential implications for users? And how can browser platforms condition the creation and distribution of activist extensions?

Suggested Citation (APA): Cao, T. (2020, October). Activist browser extensions as interface détournement: Reminding, coping, and infrastructural alignment. Paper presented at AolR 2020: The 21st Annual Conference of the Association of Internet Researchers. Virtual Event: AolR. Retrieved from https://spir.aoir.org. 


\section{Literature review}

Digital interfaces are as technical as they are political, as their design elements make an implicit claim about their intended use. Web interfaces are therefore "carriers of cultural logics and ideologies" (Ash, 2015, p. 20) with "assumptions built into [them] as the normative or 'correct' or path of least resistance" (Stanfill, 2014, 1060). Advancing a transductive approach to interface, Ash (2015) suggests that digital interfaces be seen as "sets of objects that continually encounter one another and generate particular qualities" (p. 28). By altering the conditions of such encounters, browser extensions thus "transduce" certain qualities to users. Meanwhile, Davis and Chouinard (2016) define affordances as "the range of functions and constraints that an object provides for, and places upon, structurally situated subjects" (p. 241). Four different types of affordances operate in interaction design: cognitive, physical, sensory, and functional (Hartson, 2003). This distinction is relevant in that it specifies the mechanisms through which activist extensions modify the interface and in so doing attract users' attention.

It is against this path of least resistance that activist extensions counter embedded cultural logics and ideologies. Activist extensions can be regarded as instances of "cybersituation," which involves "the appropriation, use, and reconstruction of technologies against the spectacle and other forms of domination, alienation, and oppression" (Best \& Kellner, 1999, p. 149). Echoing the aesthetic strategy of the Situationist International, détournement, or "the reuse of preexisting artistic elements in a new ensemble" (Situationist International, 2006, p. 67), activist extensions operate to disrupt and transgress. As they appropriate and reconstruct preexisting web elements into new critical ensembles, they embody what can be termed "interface détournement," creating the potential to remold passively consuming subjects into ones "fully participating in the production of everyday life, their own individuality, and, ultimately, a new society" (Best \& Kellner, 1999, p. 142).

While activist extensions operate mostly on the interface level, their creation and distribution are highly contingent on the browser platform's infrastructural services, which creates lopsided power relations between platform providers and extension developers. Identifying access to APIs as one of the primary ways in which platforms control their complementors, Nieborg and Poell (2018) ask "how platform power is operationalized through platform governance frameworks" ( $p .4285)$. This question becomes increasingly relevant as many extensions have been removed on technical or legal grounds, although some of them managed to resurface despite stringent platform control.

\section{Methods}

This study adopts a mixed-methods approach to examine activist extensions. Based on their defining characteristics, twenty extensions are identified for comparative analysis. Employing what Stanfill (2014) terms "discursive interface analysis," this paper analyzes the affordances of these extensions to examine how they counter embedded social logics through interface modifications. Critical discourse analysis is then used with the Situationist vocabulary to examine the activist capacity of browser extensions. Meanwhile, to evaluate the extensions' impact on users, user comments are collected 
from the Chrome Web Store for content analysis. Finally, semi-structured interviews are conducted with two extension developers to illustrate the relational dynamics between extension developers and the browser platform.

\section{Results}

Three preliminary results emerge from this study. First, the redirection of users' attention from the webpage to social issues is achieved through the mechanism of reminding. Through transductive processes that alter the textual, visual, or auditory elements of the user interface, activist extensions disrupt the intended use of the webpage and constantly remind users of particular social issues. Departing from the existing literature that focuses on individual extensions such as Facebook Demetricator, this study generalizes the conditions on which all activist extensions operate.

Second, the Situationist framework characterizes activist extensions, through interface détournement, as the creation of cybersituations, resisting dominant cultural logics embedded in the web interface. As a theoretical contribution, this paper coins the term "datafied spectacle," exemplified by the operation of social media platforms, as an update to Guy Debord and the Situationist International's critique of spectacle in general. Moreover, user comments illustrate that activist extensions provide users with a coping mechanism against certain online rhetoric, which sometimes channels users' attention into real-world social actions.

Third, the relationship between the browser platform and extension developers is demonstrated through the unfolding of Chrome's Manifest V3 proposal, which imposes an infrastructural alignment on the part of developers. The browser platform's official extension store also functions as a heavily gated regime of visibility, exerting control over the distribution of activist extensions. Nonetheless, some developers exploit the computational nature of digital platforms to circumvent such restrictions by distributing extensions through alternative means.

\section{References}

Ash, J. (2015). The interface envelope: Gaming, technology, power. Bloomsbury Academic.

Best, S., \& Kellner, D. (1999). Debord, cybersituations, and the interactive spectacle. SubStance, 28(3), 129-156. JSTOR. https://doi.org/10.2307/3685437

Davis, J. L., \& Chouinard, J. B. (2016). Theorizing affordances: From request to refuse. Bulletin of Science, Technology \& Society, 36(4), 241-248.

https://doi.org/10.1177/0270467617714944

Dragona, D. (2014). Counter-gamification: Emerging tactics and practices against the rule of numbers. In M. Fuchs, S. Fizek, P. Ruffino, \& N. Schrape (Eds.), Rethinking Gamification (pp. 227-250). Meson Press. 
Hartson, R. (2003). Cognitive, physical, sensory, and functional affordances in interaction design. Behaviour \& Information Technology, 22(5), 315-338.

https://doi.org/10.1080/01449290310001592587

Lievrouw, L. A. (2018). Alternative computing. In G. Meikle (Ed.), The Routledge Companion to Media and Activism (pp. 65-74). Routledge.

Nieborg, D. B., \& Poell, T. (2018). The platformization of cultural production: Theorizing the contingent cultural commodity. New Media \& Society, 20(11), 4275-4292. https://doi.org/10.1177/1461444818769694

Situationist International. (2006). Détournement as negation and prelude. In K. Knabb (Ed.), Situationist International Anthology (pp. 67-68). Bureau of Public Secrets.

Stanfill, M. (2014). The interface as discourse: The production of norms through web design. New Media \& Society, 17(7), 1059-1074.

https://doi.org/10.1177/1461444814520873

Zuboff, S. (2019). Age of surveillance capitalism: The fight for a human future at the new frontier of power. PublicAffairs. 